\title{
A Study on the Electric Fire Safety System Technology for Livestock House using RLCR Algorithm
}

\author{
Eui-bung Jeoung ${ }^{1}$, Chul-hee Lee ${ }^{2}$, Soo-mi Hong ${ }^{3}$, Hyung-kee Choi ${ }^{4}$ \\ and Kee-young Park ${ }^{5}$ \\ ${ }^{1}$ Professor, Department of Automotive \& Mechanical Engineering, \\ Howon University, Kunsan, Korea \\ ${ }^{2}$ Senior Researcher, Department of Computer Science and Engineering, \\ ILS co., LTD, Jeonju, Korea \\ ${ }^{3}$ Assistant Professor, Department of Public Health Administration \\ Vision College of Jeonju, Korea \\ ${ }^{4}$ Senear Researcher, Department of Computer Science and Engineering, \\ Sunmeditec Co., LTD, Jeonju, Korea \\ ${ }^{5}$ Professor, Department of Digital Electronics \& Information, Jeonju, Korea \\ Vision College of Jeonju, Jeonju, Korea CEO of Sunmeditec co., LTD \\ 1'bung4524@hanmail.net, ${ }^{2}$ niceiu@naver.com, ${ }^{3}$ nayasoo3@hotmail.com, \\ ${ }^{4}$ hkchoi@sunmeditec.com, ${ }^{5}$ kypark@sunmeditec.com
}

\begin{abstract}
The main causes of electrical fire are leakage, short circuit, and over capacity. Most of livestock houses are old and fire hazard is high due to the use of flammable insulating materials. The total damage caused by electric fire damage in farm household in 2010 was 6,700,000 won, which increased to 101 billion won in 2014 in Korea. Therefore, it is necessary to develop a sensor for the safity from electric fire, and notify the contents through cell phone alarm text about the fire occurrence or emergency (danger) situation. And as the fire alarm sounds, it provides a service that can respond quickly through 119 automatic notification.
\end{abstract}

Keywords: Electric fire, Livestock house, Sensor, Fire safety system EFBS(Electric Fire Band Sensor)RLCR(Relative Level Crossing Rate)

\section{Introduction}

According to the U.S. Fire Administration in 2014, electrical fires accounted for 6.3 percent, nearly 24,000 fires, of all residential fires, 11 percent of the fires where someone died and 7 percent of the fires where someone was injured. [1] Such fires bring about tragic disaster. By predicting the possibility of a fire before it occurs, it can help to prevent fire in the livestock house. Therefore, it is important to take precautions to prevent fire before it occurs. Here, we propose a fire safety system on relationship between variation of voltage and thermal in RLCR algorithm based on time and energy spectrogram in frequency domain.

\section{Related Work}

Unfortunately, livestock house fires are all too common and in great many cases, the main cause is an electrical failure of some kind. The causes of electrical fires are many; sometimes it is mechanical failure of an electrical device and sometimes it is

Received (October 7, 2017), Review Result (December 19, 2017), Accepted (February 1, 2018) 
from improper usage or design of the electrical system in the livestock hou se. Figure 1 shows the poor electrical system of a typical livestock house in Korea.
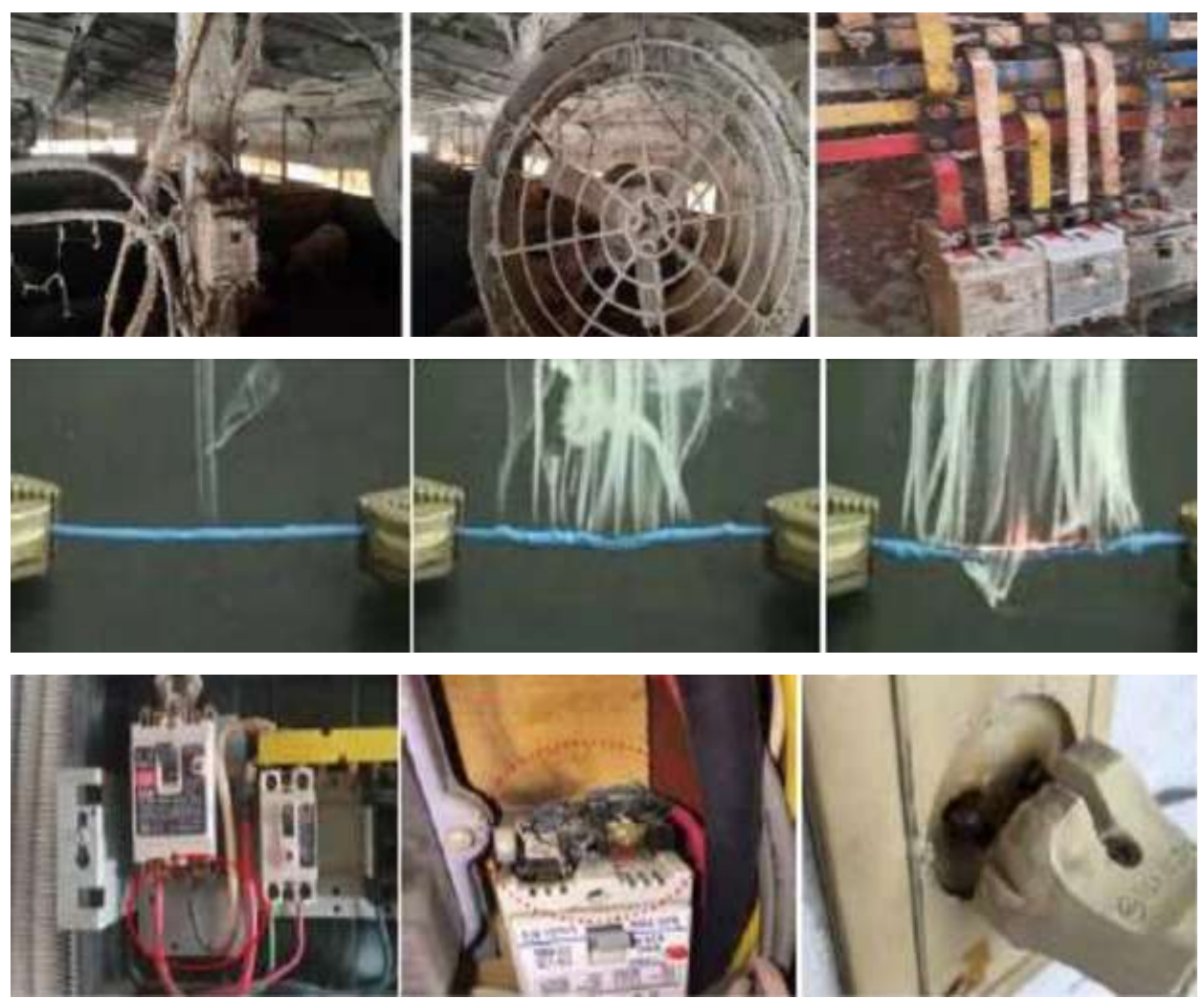

Figure 1. Poor Electrical Devices in Livestock House

The truth is that if there is a fire, someone's property is likely to be gone. Therefore, it is important to take precautions to prevent fire before it occurs. Here, we propose a fire safety system.

\section{Proposed System}

When surface partial discharge of electric device is present, tracking occurs across the surface of the insulation which is exacerbated by airborne contamination and moisture leading to erosion of the insulation. Internal partial discharge occurs within the bulk of insulation materials and is caused by age, poor materials or quality manufacturing processes. [2]

To measure electromagnetic waves, we constructed a system as shown in Figure 2. Thus, this study offers a EFBS(Electric Fire Band Sensor) to measure partial discharge of power cable and socket. The reason for the multiple band antenna is that the frequency range variations $(20 \sim 1000 \mathrm{MHz})$.

Figure 2 displays the system block diagram of the detecting electromagnetic wave \& $\mathrm{PD}$ (partial discharge). Three antennas have the three frequency bands. The frequency band of channel 1 is from $20(\mathrm{MHz})$ to $100(\mathrm{MHz})$, Channel 2 is $100(\mathrm{MHz}) \sim 500(\mathrm{MHz})$ and channel 3 is $500(\mathrm{MHz}) \sim 1000(\mathrm{MHz})$. So, antenna sensor detects discharge frequency induced by electric field. The discharge frequency includes a carrier. The acoustic signal is extracted through tuning.

Thus, this study offers a sensor to measure PD or electromagnetic wave of electric socket, and to analyze and diagnose the data collected from it. 


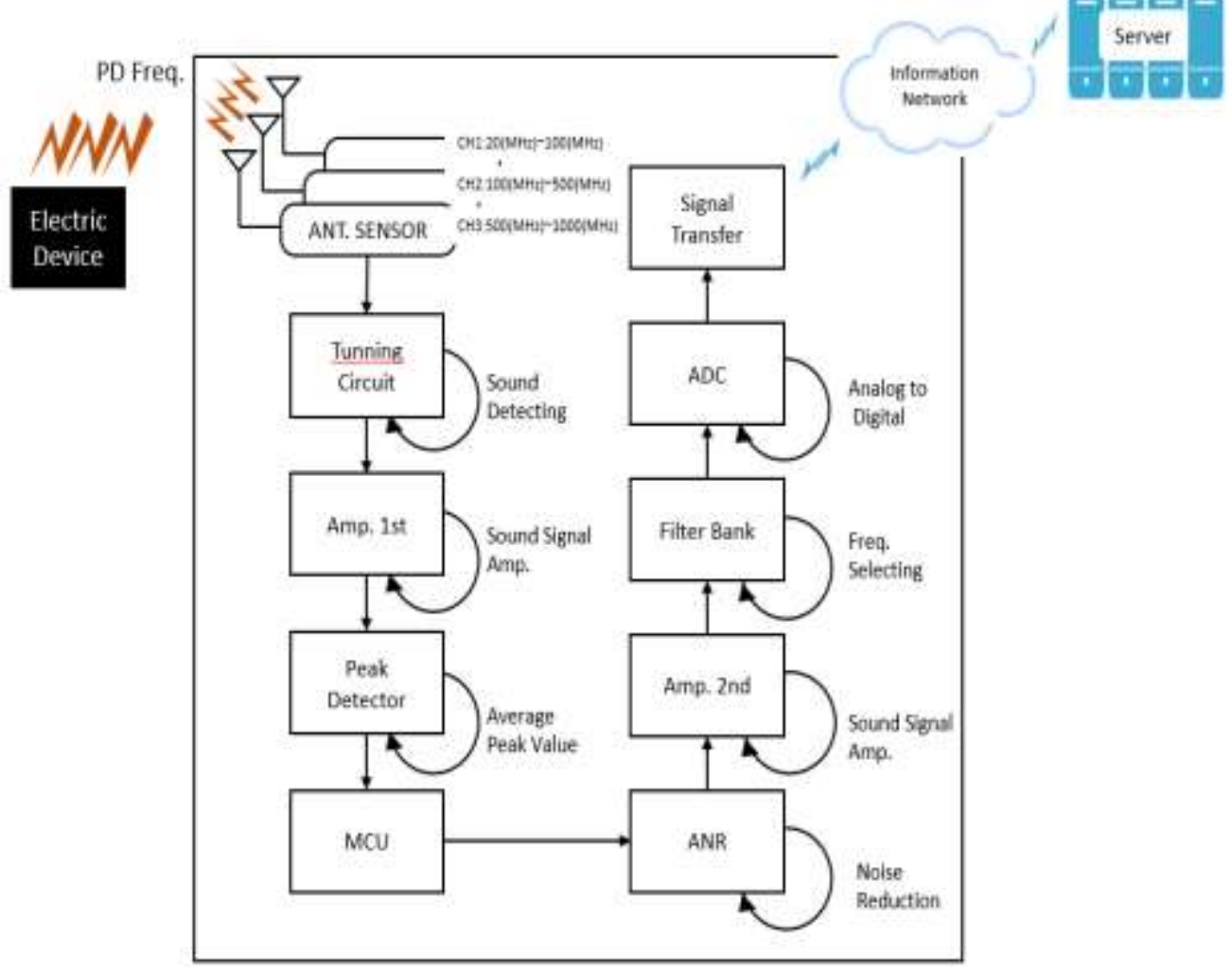

Figure 2. System Block Diagram of the Detecting Electromagnetics \& PD

For collecting electromagnetic wave or PD(partial discharge) Data, the system in Figure 3 utilized the partial discharge sound analysis software designed via Visual C++ by the flow chart in Figure 3. Electromagnetic wave or PD data entered by the sensor pass through the hard filter in the detecting electromagnetic system in Figure 2 and then, through ADC to the USB port of the server while being converted from analog to digital.

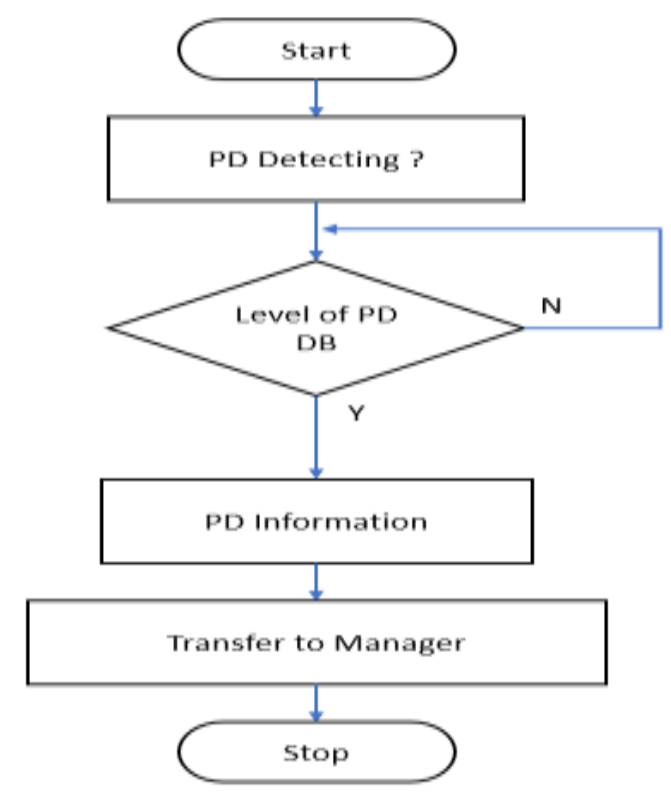

Figure 3. Flow Chart of Electromagnetic Wave or PD Checking 
Figure 4 was to gather data from the detected digital signal through the system in Figure 2. In here, the data was recorded in 16bit, 20(KHz). [3] The electromagnetic data collection system was installed in test bed system of Sunmeditec co., ltd.

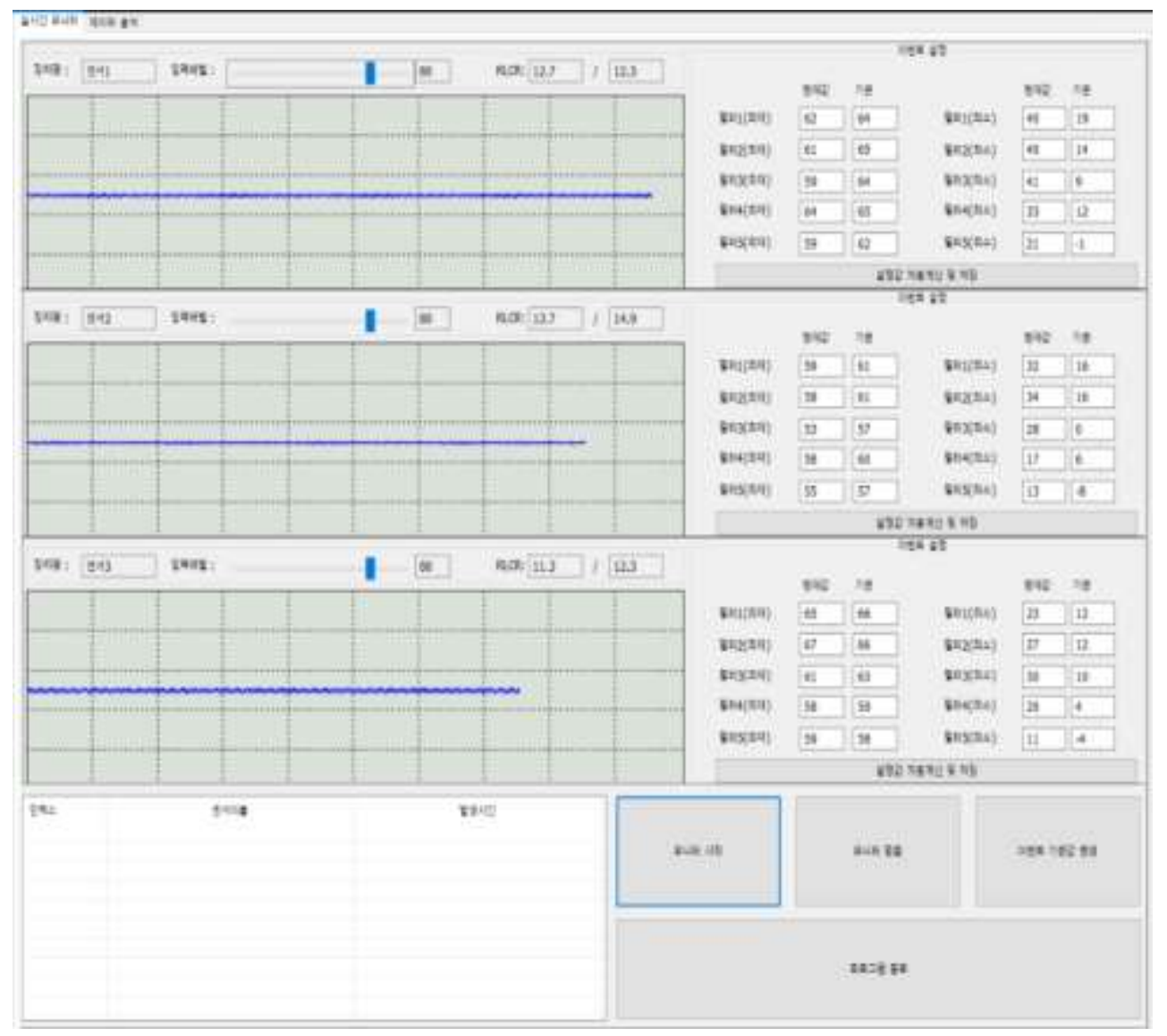

Figure 4. Data Collection and Analysis Software for ac 220(V)

\section{Simulation}

The data on electromagnetic wave sound generated from three sensors (Ch 1, 2, and 3) are collected for analysis and diagnosis. In order to analyze the electromagnetic wave sound data, the process in Figure 3 was performed. It detects the induced current through EFBS and amplifies it, and convert the current to voltage to send to microprocessor. The microprocessor performs Fourier transform (FFT), bigger signal voltage among the two, and ANR (Ambient Noise Rejection) by covering it with Hamming Window. Hamming window was utilized as window and its size is 256 samples for one frame. The frequency analysis used 65,536 point FFT.

The filter bank selects the optimum electromagnetic wave signal to transform in digital format(ADC). This data is sent to the computer in order to analyze and diagnose at time domains in real time.

A block diagram of analysis device is shown in Figure 5. The electromagnetic wave signal is processed on the monitor and a danger signal for electromagnetic wave detection is informed to the user. 


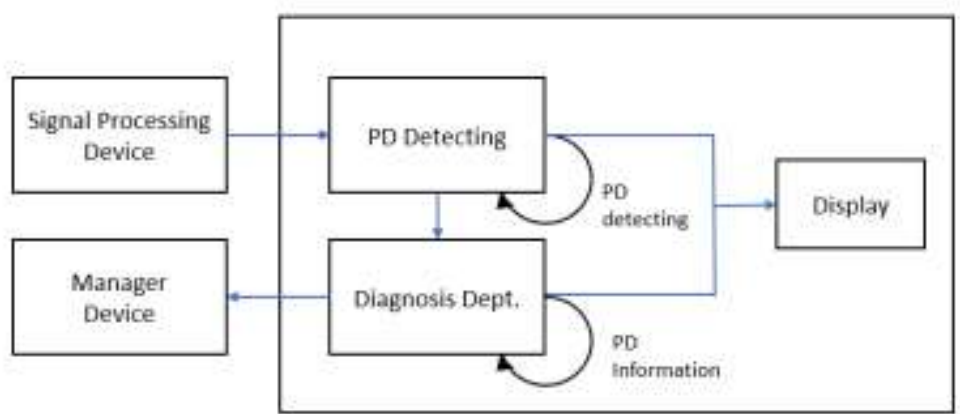

Figure 5. Block Diagram of Analysis Device

The test bed is set to ac 220(V) as shown in Figure 6. In order to analyze the EFBS acoustic data, the process in Figure 3 is performed.

As for the relative level cross rate (RLCR), a threshold figure for each frame was set, and the number of the signal wave form crossed the threshold was counted as shown in the formula (1) [4].

$$
\begin{aligned}
& R(m)=\frac{1}{N} \sum_{n=m \cdot N+1}^{m}\left(\frac{\mid \operatorname{sgn}\left[x(n)-L_{l t}\right]-\operatorname{sgn}\left[x(n-1)-L_{t h} \mid\right.}{2}\right) w(m-n) \\
& \operatorname{sgn}[x(n)]= \begin{cases}1 & x(n) \geq 0 \\
-1 & x(n)<0\end{cases}
\end{aligned}
$$

Also, the frequency range is divided into three steps for spectrogram analysis of EFBS acoustic data. The acoustic data is divided energy range in frequency band. The formula (2) extracted the parameters of dbML and dbHL.

$$
\begin{aligned}
\mathrm{dbML} & =\frac{\text { Medium Spectral Energy }}{\text { Low Spectral Energy }} \\
\mathrm{dbHL} & =\frac{\text { High Spectral Energy }}{\text { Low Spectral Energy }}
\end{aligned}
$$

Based on these parameters of $\mathrm{dbML}$ and $\mathrm{dbHL}$, it determines dbML parameter and dbHL parameter calculated from the sound signal of normal condition as normal or abnormal whether the figures exist in the error range or not. The determined parameters were shown in color (spectrogram). [4]

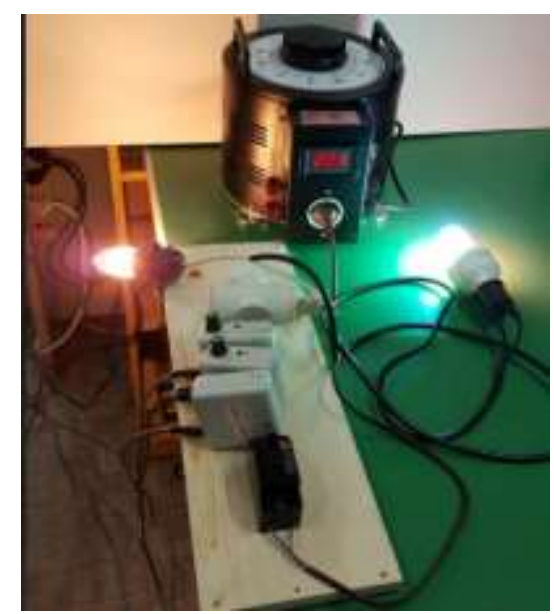

Figure 6. Combination of Sensor and Test Bed Device for AC 220(V) 
Figure 7 displays RLCR values in the normal section and abnormal section (where electromagnetic wave occurred) in terms of the three positions (Channel 1, 2 and 3). RLCR values in the normal partial discharge data frame were ranged from $140(\mathrm{~V})$ to $220(\mathrm{~V})$ in reference RLCR minimum (11.7 12.5), and the RLCR values in the abnormal section (PD) were ranged from $220(\mathrm{~V})$ to $300(\mathrm{~V})$ or under 140 voltage in reference RLCR minimum (11.7 12.5). Here is an important point. The temperature range of the fluorescent lamp at the voltage 220 where the electromagnetic wave starts to be generated is at least 111 degrees and the maximum is 126 degrees. On the other hand, incandescent lamps go up from 272 degrees to 326 degrees. The minimum and maximum temperature of fluorescent and incandescent lamp are shown in Figure 8. If the check is performed in the same way, it is possible to confirm the difference in channel 2 and 3 . When we generate electromagnetic waves and the voltage increases, the fluorescent lamps are not a problem, but incandescent lamps can cause a fire. Figure 8 shows the electromagnetic wave or PD occurred in frequency domain.

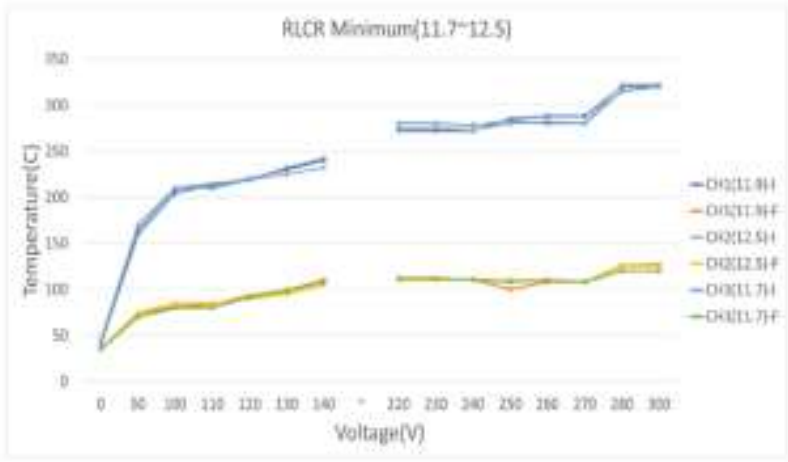

(a)

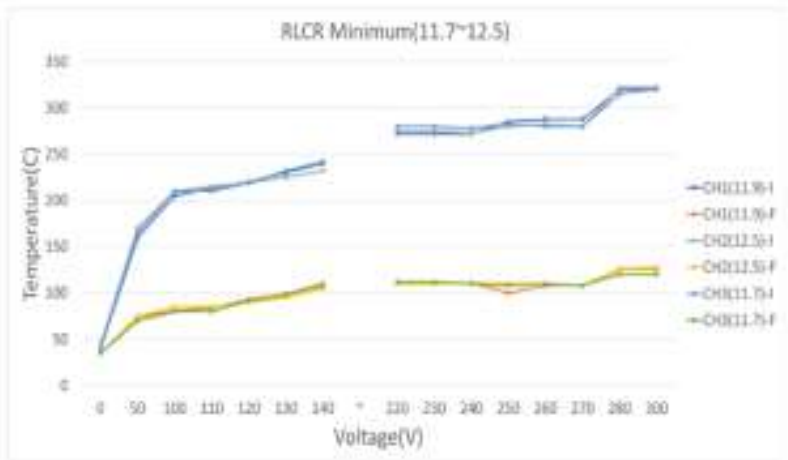

(b)

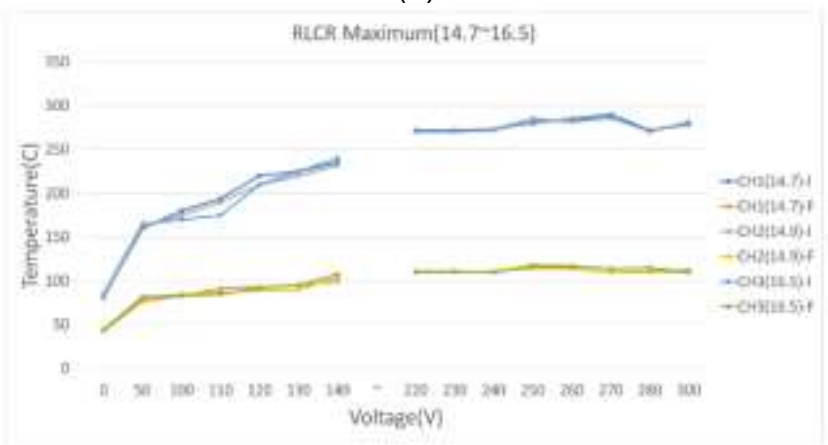

(c)

Figure 7. Comparison of the Voltage and Temperature of Fluorescent Lamp and Incandescent Lamp in the RLCR Value 

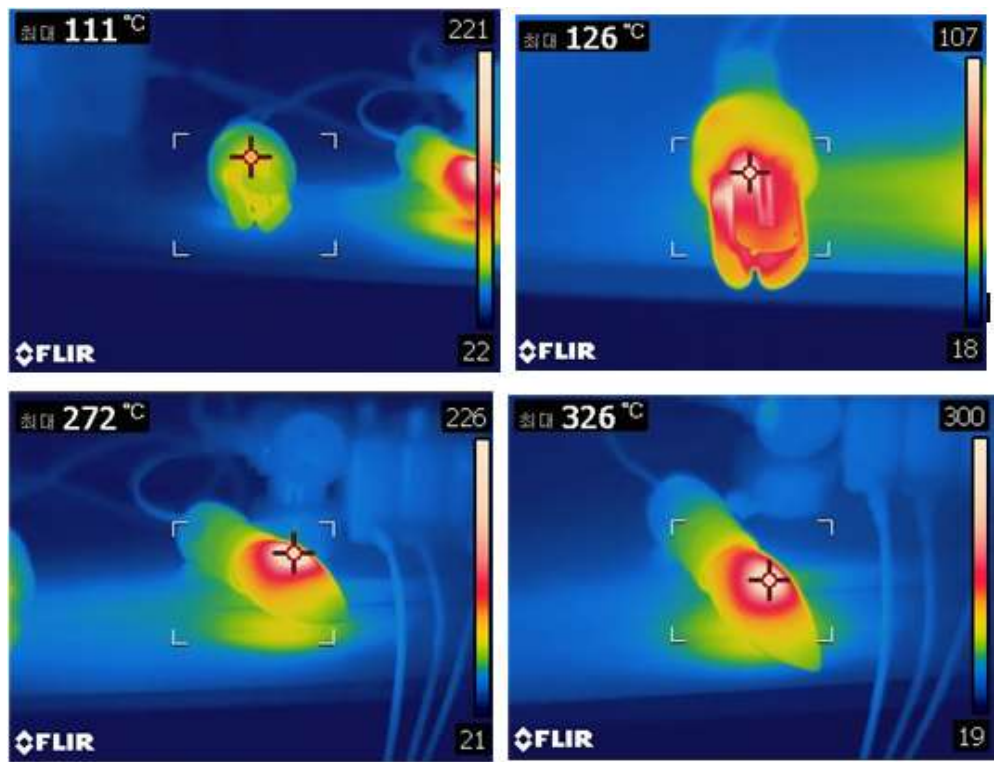

Figure 8. Comparison of the Temperature of Fluorescent Lamp and Incandescent Lamp

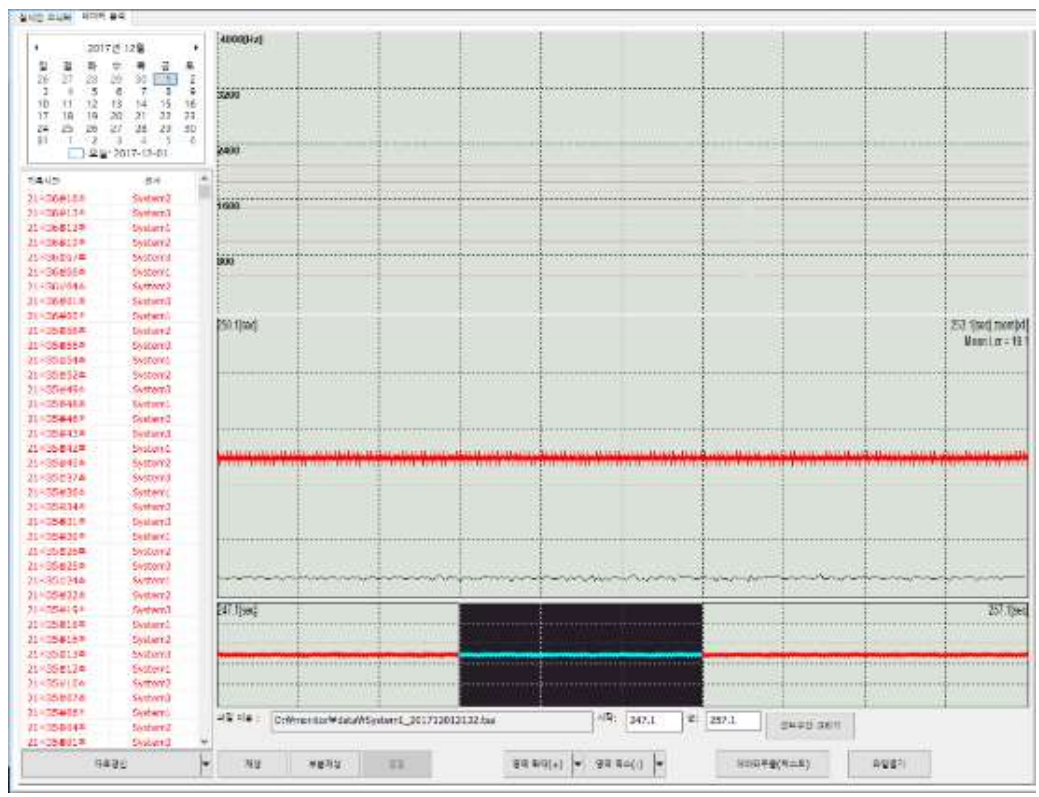

Figure 8. Variation of RLCR Level in Frequency Domain

Figure 9 shows that the state of the voltage is abnormal due to electromagnetic waves. Monitor(a) indicates a voltage problem at $245(\mathrm{~V})$ or higher and monitor(b) indicates a voltage problem at $110(\mathrm{~V})$ or lower in the time domain. Also (c) and (d) are displayed voltage in frequency domain. 


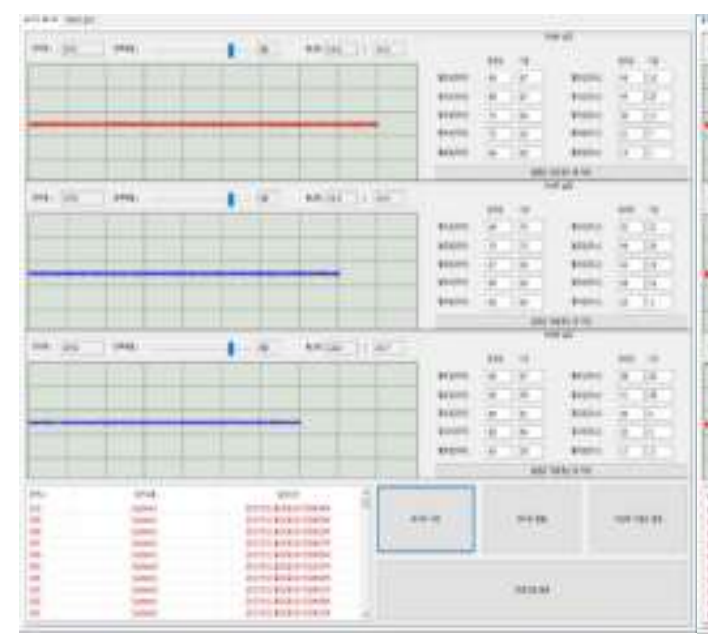

(a)

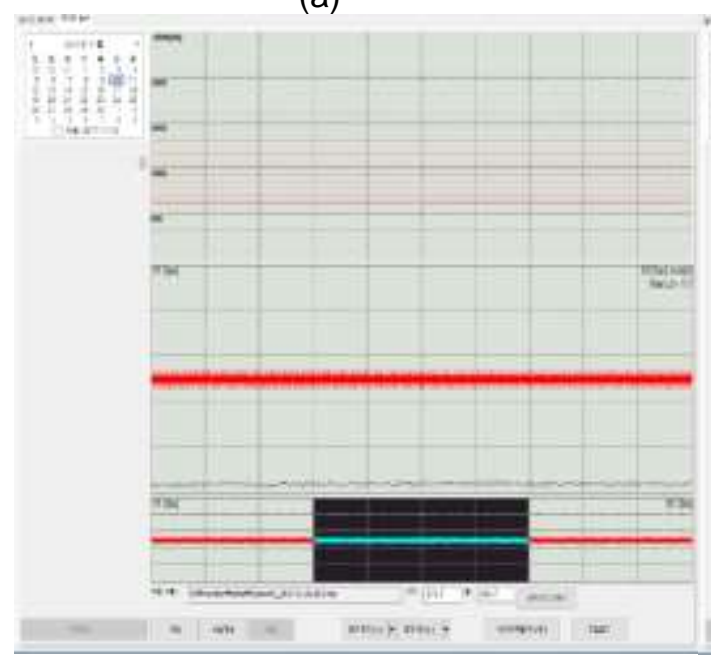

(c)

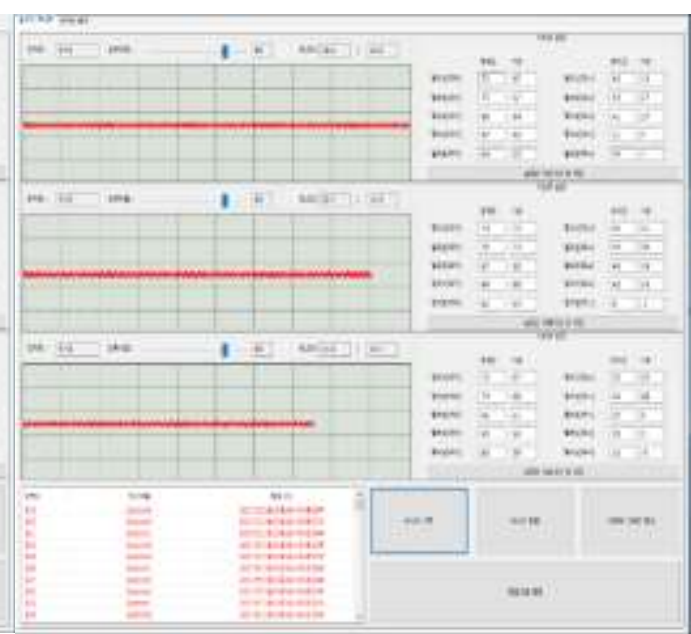

(b)

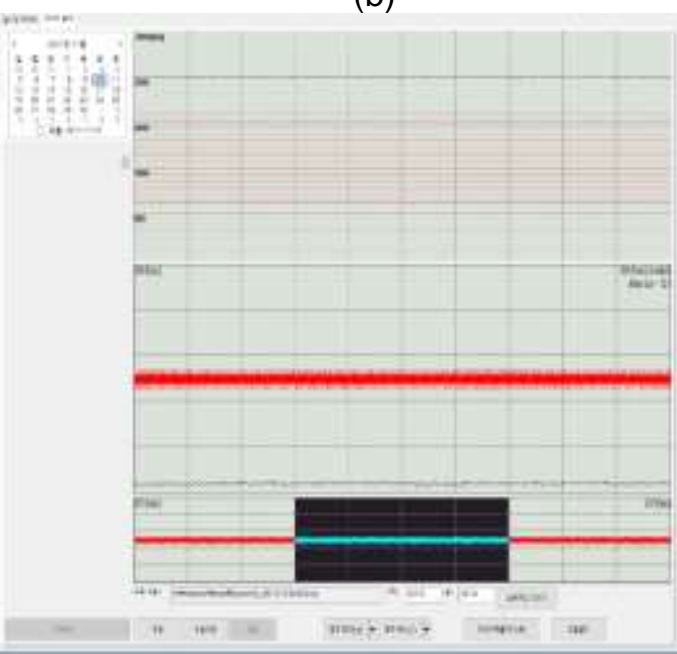

(d)

Figure 9. Comparison of Detecting Sensor $(a, b)$ and Frequency Domain (c, d) of AC 220(v) Source

Here, we present an experiment with another test bed. This is the relationship among the voltage variation of electromagnetic wave sounds in the RLCR values.

Figure 10 displays RLCR values in the normal section and abnormal section (where electromagnetic wave occurred) in terms of the three positions (Channel 1, 2 and 3). RLCR values in the normal partial discharge data frame were ranged from $150(\mathrm{~V})$ to $230(\mathrm{~V})$ in reference RLCR minimum (11.8 13.7) and the RLCR values in the abnormal section (PD) were ranged from $240(\mathrm{~V})$ to $300(\mathrm{~V})$ or under 140 voltage in reference RLCR minimum (11.8 13.7). If the check is performed in the same way, it is possible to confirm that the difference in channel 2 in the reference RLCR medium (13.4 14.5) and in channel 3 in the reference RLCR maximum (14.6 19.9) means relative variable levels, and it can change the voltage values. 


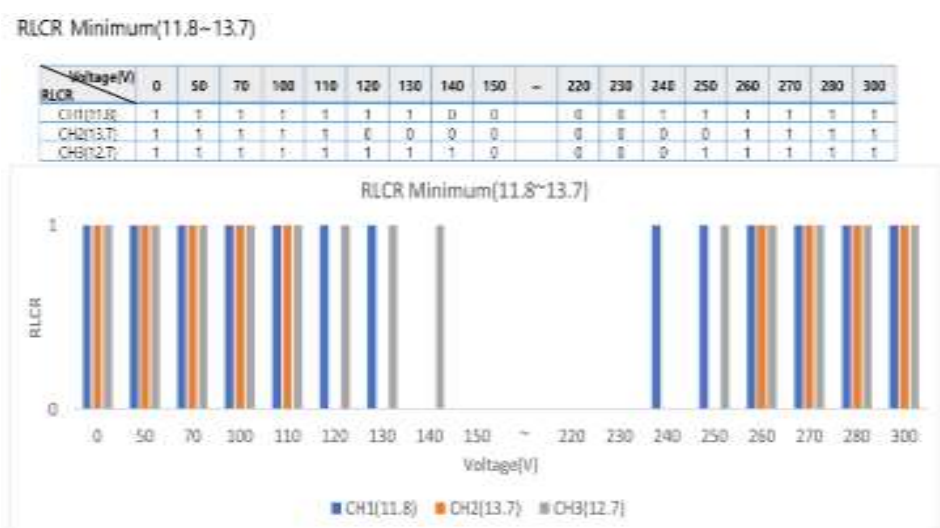

(a)

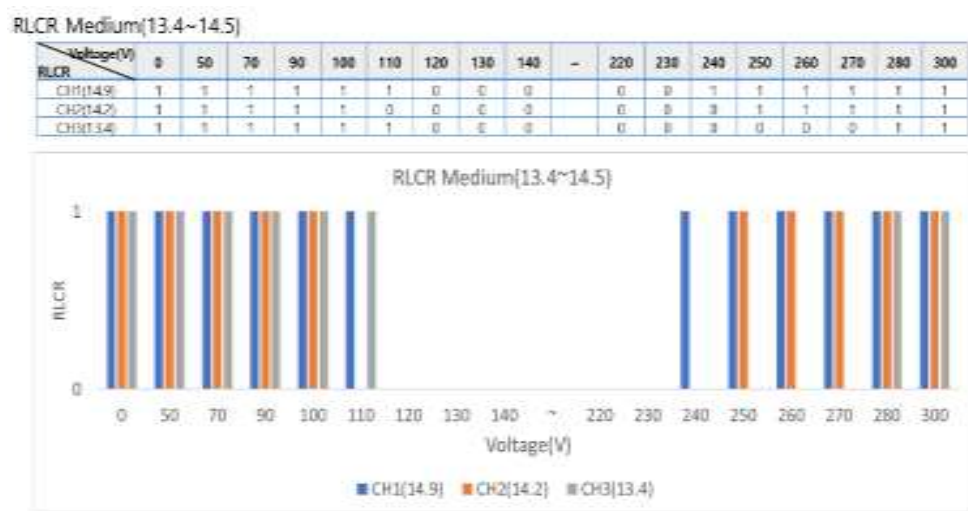

(b)

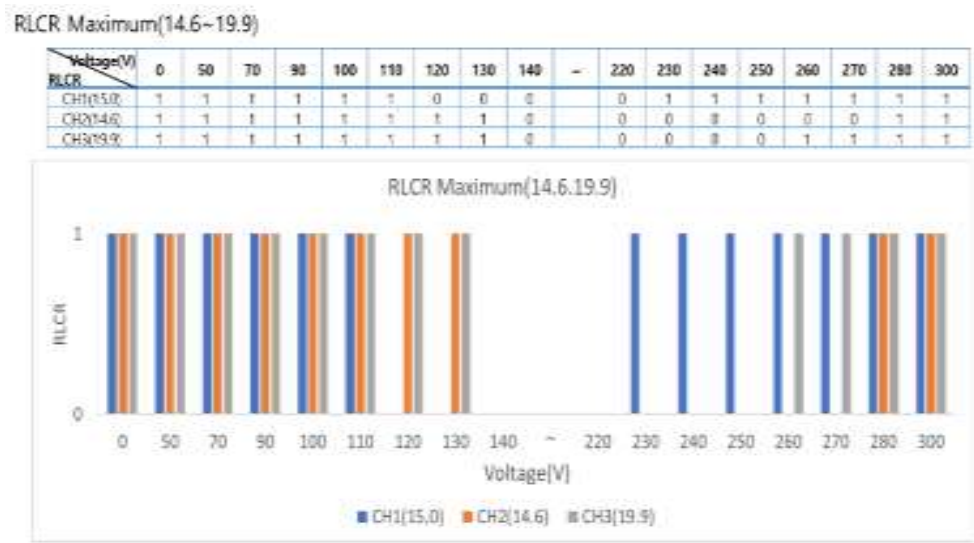

(c)

Figure 10. Comparison of the Voltage Variation of Electromagnetic Wave Sounds in the RLCR Values

Figure 11 displays the data variation of electromagnetic wave sounds in the reference RLCR minimum (11.8 13.7) of time domain. In this graph, it confirms that the partial discharge was occurred according to the RLCR values in real time.

Also, Figure 11(a) is displayed the normal state of the electromagnetic wave at the socket voltage $150(\mathrm{~V}) \sim 230(\mathrm{~V})$ and Figure $11(\mathrm{~b})$ and $(\mathrm{c})$ are shown the abnormal state of the electromagnetic wave at the socket voltage $250(\mathrm{~V})$ more or below $110(\mathrm{~V})$. 


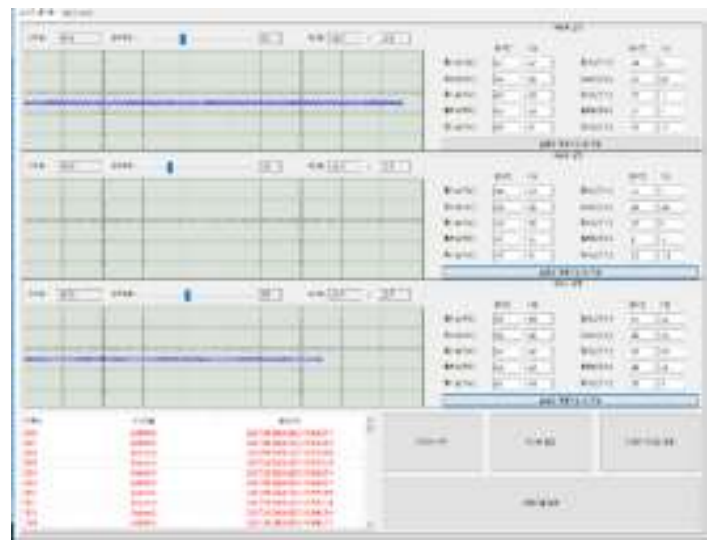

(a)

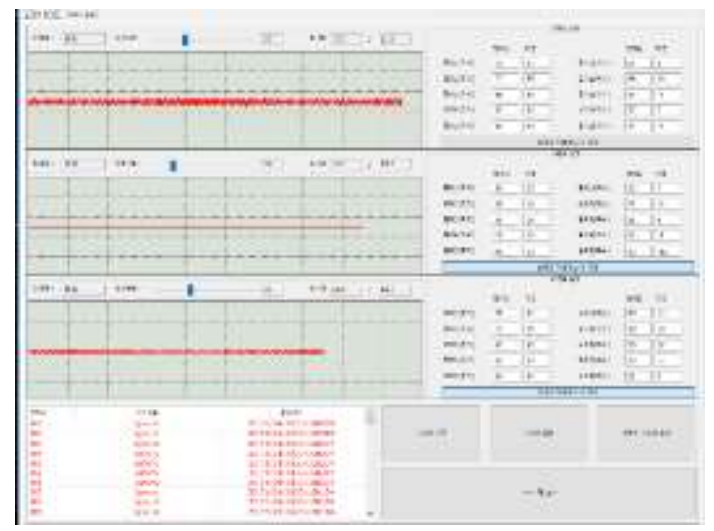

(b)

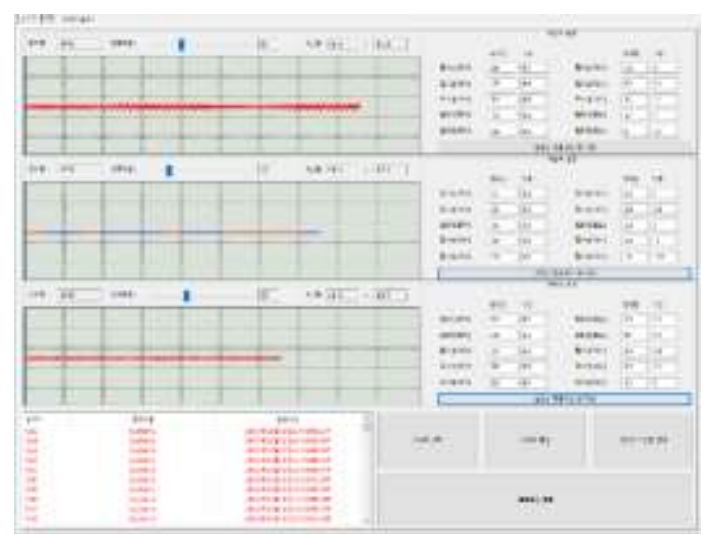

(c)

Figure 11. Comparison of the Data Variation of Electromagnetic Wave Sounds in the Time Domain

\section{Conclusion}

As a result of repeating the simulation, it is confirmed that the event occurs in RLCR algorithm when the influence of electromagnetic waves shows the relation between voltage and thermal. The problem occurs in the upper $220(\mathrm{~V})$ or lower $140(\mathrm{~V})$ commercial power supply. Also, it is verified that the event occurs in the time domain and the frequency domain when the voltage is abnormal. The problem occurs in the upper $20 \%$ or lower $50 \%$ of the commercial power supply.

And there is no temperature change within a voltage range of $140(\mathrm{~V})$ to $220(\mathrm{~V})$ and is not affected by electromagnetic waves. However, at other voltages, fluorescent lamps are not a problem, but incandescent lamps have a high probability of fire. Therefore, we 
confirmed the importance of prediction and notification system according to the variation of voltage, that is the generation of electromagnetic wave in a poor housing environment.

As a result, it has been confirmed that fire can be prevented by predicting electric fire in a poor housing environment and informing the user.

The incident is transmitted to the user by text. Figure 12 shows the alarm message by smartphone when electric fire is predicted.

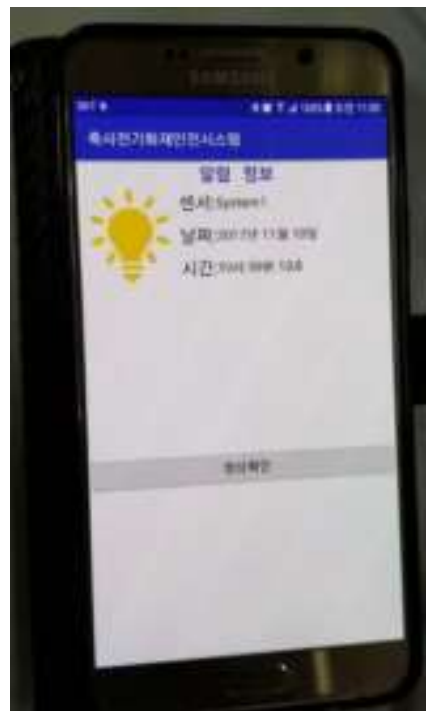

\section{Figure 12. Alarm Message is Transmitted from the Fire Safety System}

\section{Acknowledgments}

This research was supported by the academic research of Howon University of academic research and JICA (Jeonju IT \& CT industry Promotion Agency) funding.

This paper is a revised and expanded version of a paper entitled "A Study on the Electric Fire Safety System Technology for Livestock House" presented by Eui-bung Jung, Chulhee lee, Soo-mi hong, Hyung-kee Choi, Kee-young Park at Jeju National University, Korea, December 1-2, 2017.

\section{References}

[1] http://www.firerescue1.com

[2] N. Davies and S. Goldthorpe, "Testing distribution Switchgear for Partial Discharge in the Laboratory and the Field”, 20th International Conference on Electricity Distribution, (2009) June, pp. 8-11.

[3] K. Y. Park, H. K. Choi, C. H. Lee and S. M. Hong, "A Study on a Partial Discharge Diagnostic System for Power Cable using RLCR", KEPCO Journal on Electric Power and Energy, vol. 2, no. 1, (2016) March, pp. 43-47.

[4] K. Y. Park, H. K. Choi, C. H. Lee, S. M. Hong and E. B. Jung, "A Partial Discharge Diagnostic System for Power Cable using FBDS”, IEIE, vol. 54, no. 1, (2017) January, pp. 157-163.

[5] F. H. Kreuger, E. Gulski and A. Krivda, "Classification of Partial Discharge", IEEE Trans. On Insul, vol. 28, no. 6, (1993), pp. 917-931.

[6] H. K. Kin, "Study on the thermal property of covalently networked carbon nanotube mats", Seoul University, (2014) February.

[7] M. Giyoaki, "Development of a high performance portable PD detection device", Product and Electrics, (2006) December.

[8] P. J. Harrop, "Dielectrics", Butterworths, London, (1972).

[9] H. Kawada, M. Honda, T. Inoue and T. Amemiya, "Patrial discharges automatic monitor for oil-filled power transformer", IEEE Transaction on Power Apparatus and System, vol. PAS-103, no. 2, (1984), pp. 422.

[10] S. Gorman, "Electricity Grid in U.S. Penetrated by Spies", The Wall Street Journal, Page A1, (2009) April

[11] http://www.eatechnology.com/. 


\section{Authors}

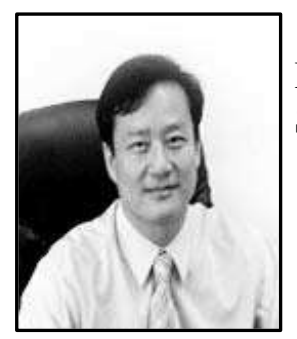

Eui-bung Jung, Professor, Department of Automotive \& Mechanical Engineering, Howon University, Kunsan, Korea

Significant area of interest: Digital Signal Processing, IOT

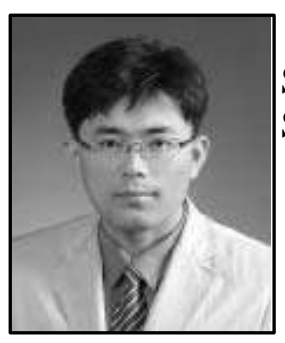

Chul-hee Lee, Senior Researcher, Department of Computer Science and Engineering, ILS co., LTD, Jeonju, Korea Significant area of interest: Speech Signal Processing

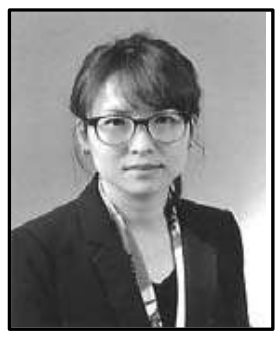

Soo-mi Hong, Assistant Professor, Department of Public Health Administration Vision College of Jeonju, Korea Significant area of interest: u-Healthcare system, IoT

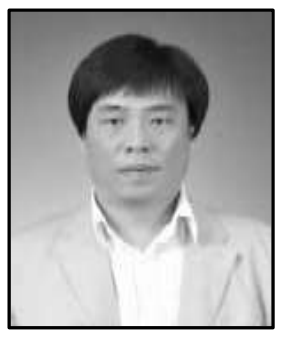

Hyung-kee Choi, Senior Researcher, Department of Computer Science and Engineering, Sunmeditec co., LTD, Jeonju, Korea Significant area of interest: Signal Process, Application SW

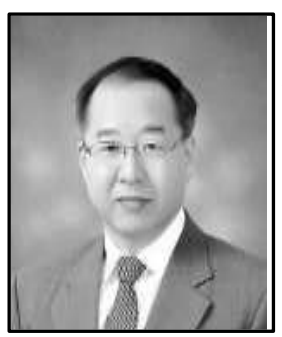

Kee-young Park, Professor, Department of Digital Electronics \& Information, Vision College of Jeonju, Jeonju, Korea CEO of Sunmeditec co., LTD, Jeonju, Korea

Significant area of interest: Signal Process \& System, Bio Tech. 